\title{
Endoscopic versus open harvesting of radial artery for CABG
}

\author{
Mohamed Abdel Hafez Foulyo
}

\begin{abstract}
Background: Endoscopic harvest of the radial artery avoids long forearm incisions and has better cosmesis compared to the open technique. The objective of this study was to compare the short-term results and woundrelated complications of endoscopic radial artery harvest versus open technique.

Results: From 2013 to 2017, 800 patients had coronary artery bypass grafting; 88 patients of them had radial artery harvesting (11\%). Two groups were included in the study according to the surgeon preference, endoscopic radial harvest (group 1, $n=30 ; 3.75 \%$ of total CABG patients) and open harvest (group 2, $n=58 ; 7.25 \%$ of total CABG patients). Group 1 had more males (25 (83.33\%) vs. 35 (60.34\%); $p=0.028$ ). There was no difference in the preoperative comorbidities between both groups. The duration of the harvest was significantly longer in group 1 (median 40 min ranges from 38 to $42 \mathrm{~min}$ vs. $49 \mathrm{~min}$ ranges from 47 to $52 \mathrm{~min}$ in groups 1 and 2 , respectively; $p<0.001$ ). The operative time was longer in group 1 (median 302.5 min ranges from 295 to 310 min vs. 277 min ranges from 273 to 280 min in groups 1 and 2, respectively; $p<0.001$ ). The hospital stay in the endoscopic radial artery harvest group was significantly shorter than that of open technique (median 7 days ranges from 6 to 7 days vs. 7.5 days ranges from 7 to 9 days; $p<$ 0.001). There was no significant difference in the postoperative complications between both groups. One case (3.3\%) was transformed from the endoscopic to open technique due to uncontrolled bleeding. Endoscopic technique was associated with more patients presenting with hand numbness (6 cases; $20 \%$ versus 3 cases 5.2\%) and radial nerve injury ( 2 cases; $6.6 \%$ versus none), while open technique showed more cases of local hematoma (8 cases; $13.8 \%$ versus 1 case; $3.3 \%$ ) and wound infection (6 cases; $10.34 \%$ versus none); $p>0.05$.
\end{abstract}

Conclusion: Endoscopic radial artery harvest is associated with shorter harvest time and shorter hospital stay. Endoscopic radial artery harvest is a safe technique with good short-term outcomes. Longer follow-up is recommended.

Keywords: Endoscopic radial artery harvest, Coronary artery bypass grafting, Radial artery graft

\section{Background}

Radial artery graft is associated with good long-term outcomes when used to bypass critical coronary artery stenosis in a young patient $[1,2]$. The radial artery has several advantages as a conduit in coronary artery bypass grafting (CABG). The radial artery can be used as an alternative to the right internal mammary artery (RIMA) in certain circumstances as in diabetic, obese patients and patients with chronic obstructive pulmonary disease (COPD) where bilateral harvesting of the internal mammary arteries increases the risk of sternal infection [3]. The radial artery is more prone to spasm from the

\footnotetext{
Correspondence: mhafez1982.gf@gmail.com
}

Cardiothoracic, Cairo University, Cairo, Egypt competitive flow because of the thick muscular wall; therefore, it is advised to put the radial artery on critical lesions with the very faint native antegrade flow [4]. The proximal end of the radial artery can be anastomosed directly to the aorta or as a composite $\mathrm{T}$ or $\mathrm{Y}$ graft to the internal mammary artery [5].

Two techniques were described for the harvesting of the radial artery: open and endoscopic. Open harvest of the radial artery involves large longitudinal forearm incision with the potential of longer harvest time and more wound-related complications [6]. Endoscopic vessel harvesting was introduced in 1990, where it was used for harvesting of the saphenous vein. Then in 2001, it was used in the harvesting of the radial artery. By the year 2005 , it was used over a large scale for the harvesting of 
both saphenous vein and radial artery, and now, about $80 \%$ of CABG patients at USA hospitals have both saphenous vein and radial artery harvested endoscopically [7].

\section{Methods}

\section{Study design and patients}

This research paper is a retrospective cohort study that was conducted in King Faisal Specialized Hospital over 5 years, starting from January 2013 till January 2017. During this period, 800 patients had CABG; $11 \%$ of them $(n=88)$ had radial artery conduits. The data of 88 patients who underwent elective CABG with radial artery as an arterial conduit were collected. The patients were divided into two groups; group 1 included patients who had endoscopic radial artery harvest $(n=30 ; 3.75 \%$ of total CABG patients), and group 2 included the patients who had open radial artery harvest $(n=58 ; 7.25 \%$ of total CABG patients). Patients were assigned to either group according to the surgeon's preference and the availability of the endoscope.

The data collected included age, sex, and comorbidities, such as hypertension and diabetes. Operative data included the duration of the radial artery harvest and the operative time. Postoperative data included the complications in the form of wound hematoma, reexploration, wound infection, local neurological complications from nearby dorsal radial nerve injury with numbness on the dorsum of the hand, and its reflection on hospital stay.

Data collection was approved by the Institutional Review Board at King Faisal Specialized and Research Center, and the patient's consent to participate in research was obtained during procedure consent.

\section{Inclusion criteria}

We included patients who had elective three or four vessels CABG and less than 60 years old. The preoperative Allan test was performed and showed equivocal dependence of the arterial supply of the hand on both radial and ulnar artery. We used the radial artery of the nondominant hand. The radial artery was used to graft the obtuse marginal $(\mathrm{OM})$ with a critical lesion of the circumflex artery, and the proximal end of the radial artery was anastomosed directly to the aorta.

\section{Exclusion criteria}

We excluded patients who had an emergency CABG or a concomitant procedure CABG. Patients who had radial dependent hand circulation and those who had sequential radial grafting or $\mathrm{T}$ or $\mathrm{Y}$ radial anastomosis to LIMA were excluded.

\section{Surgical procedures}

\section{Endoscopic harvesting}

Endoscopic harvesting was performed using the VASOVIEW $^{\circ}$ Endoscopic Vessel Harvesting System (MAQUET Cardiovascular, Santa Clara, CA.). A 3-cm longitudinal incision is made just proximal to the wrist crease over the radial artery that is identified by its pulsation (Fig. 1). Then, direct dissection locally through the lateral fascia to identify the radial artery and its venae comitantes, which are dissected as one pedicle to avoid direct trauma of the radial artery. The endoscope with the conical tip is advanced directly over the radial artery to allow the insertion of the port (Fig. 2). The port was inflated with air to create a seal. $\mathrm{CO} 2$ was insufflated at a pressure of average 10-12 $\mathrm{mmHg}$ and a flow rate of about $4 \mathrm{~L} / \mathrm{min}$ to create a tunnel [6]. Dissection using the conical tip started from the

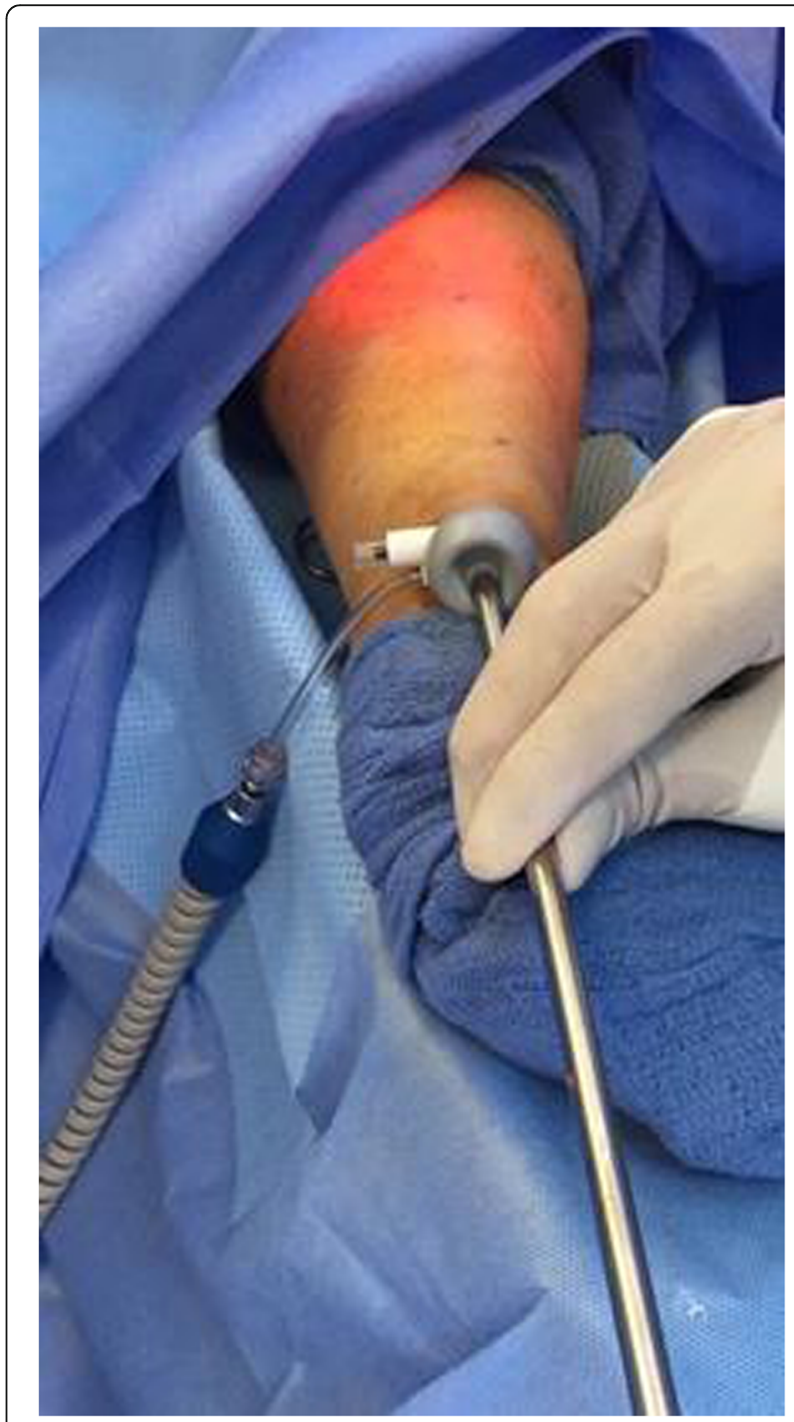

Fig. 1 The endoscopic port with the conical tip inserted in the forearm 


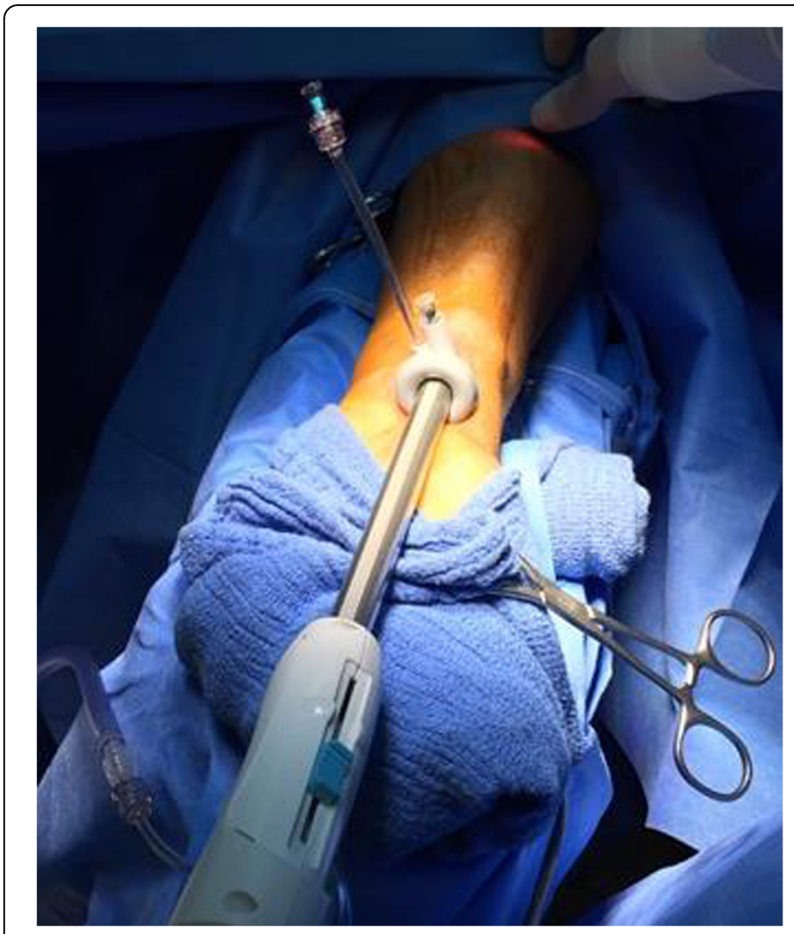

Fig. 2 The VasoView cannula inserted through the forearm

posterior aspect of the radial artery at first then the anterior aspect. The conical tip was removed from the end of the endoscope, and the endoscope was placed into the

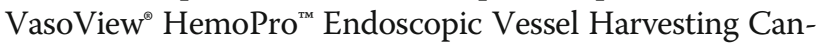
nula. Fasciotomy was performed using direct energy force. Dissection of the tissues was performed by grasping it between both jaws of the cannula together with pulling and rotation of the tool to apply direct tension. The branches were captured between both Jaws by pulling the Toggle into the middle position. The radial artery pedicle can be divided and ligated in the antecubital fossa with an 11blade using a vessel loop endoscopic technique [8]. The radial artery is prepared by direct flushing with papaverine and clipping of the branches by direct clip applier [8].

\section{Open harvesting}

Conventional open radial artery harvesting technique was performed using the method described by Reyes and colleagues through a forearm incision along the course of the radial artery of the nondominant hand starting from the felt pulsation of the artery till its origin from the brachial artery. It was harvested as one pedicle with its venae comitantes with less manipulation of the graft to avoid direct blunt trauma. Dissection of the pedicle was performed by using low-intensity monopolar electrocautery, and the control of the side branches was done using vascular clips [9]. Closure of the forearm was done over a direct drain with one layer of subcutaneous tissue using Vicryl without closure of the fascia to prevent compartmental syndrome if hematoma formed. After closing, a direct elastic bandage was applied and wrapped around the forearm [9].

In both techniques, dissection was done without heparin, and division of the radial artery was done after heparinization. After finishing harvesting, a direct drain was inserted beside the wrapping of the forearm which was done with direct elastic stocking after the closure of the forearm incision.

\section{Statistical analysis}

All analyses were performed using STATA 16 software (Stata-Corp, College Town, TX, USA). Continuous variables were described as median (50th percentile) and 25th-75th percentile and were compared between group 1 (endoscopic radial artery harvest) and group 2 (open radial artery harvest) using the Wilcoxon rank-sum test. Categorical variables were presented as number and percent and were compared using the chi-square or Fisher exact test if the expected frequency is less than 5 . The analysis was bilateral. A $p$ value of less than 0.05 was considered significant.

\section{Results}

Group $1(n=30)$ had 25 males $(83.33 \%)$ which were significantly higher than group $2(n=58 ; 35(60.34 \%) ; p=$ 0.028 ). There was no significant difference in preoperative comorbidities between both groups (Table 1). The duration of the harvest was significantly shorter in group 1 (median $40 \mathrm{~min}$ vs. $49 \mathrm{~min}$ in groups 1 and 2, respectively; $p<0.001$ ) (Fig. 3). The operative time was longer in group 1 (median $302.5 \mathrm{~min}$ vs. $277 \mathrm{~min}$ in groups 1 and 2, respectively; $p<0.001$ ) (Fig. 4 and Table 2). One patient was transformed into an open approach as one branch of radial artery avulsed during dissection with arterial bleeding that obscured the field of vision through the endoscopic camera. The hospital stays in endoscopic harvesting were significantly shorter than those of open harvesting ( $p<$ 0.001). Although they did not reach a significant level, the complication rate was higher in group 2 except hand numbness, which occurred more frequently in group 1 (20\% vs. $5.2 \%$; $p=0.057$ ) (Table 3 ).

Table 1 Preoperative patient's characteristics

\begin{tabular}{llll}
\hline & Group 1 $(n=30)$ & Group 2 $(n=58)$ & $p$ \\
\hline Age (years) & $52(48-57)$ & $55(48-58)$ & 0.275 \\
Male & $25(83.33 \%)$ & $35(60.34 \%)$ & 0.028 \\
Diabetes mellitus & $21(70 \%)$ & $46(76.31 \%)$ & 0.331 \\
hypertension & $19(63.33 \%)$ & $42(72.41 \%)$ & 0.381 \\
Renal failure & $1(3.33 \%)$ & $6(10.34 \%)$ & 0.415 \\
Previous stroke & $2(6.67 \%)$ & $3(5.17 \%)$ & $>0.99$ \\
\hline
\end{tabular}

Continuous variables are presented as median and 25th-75th percentiles and categorical variables as number and percent 


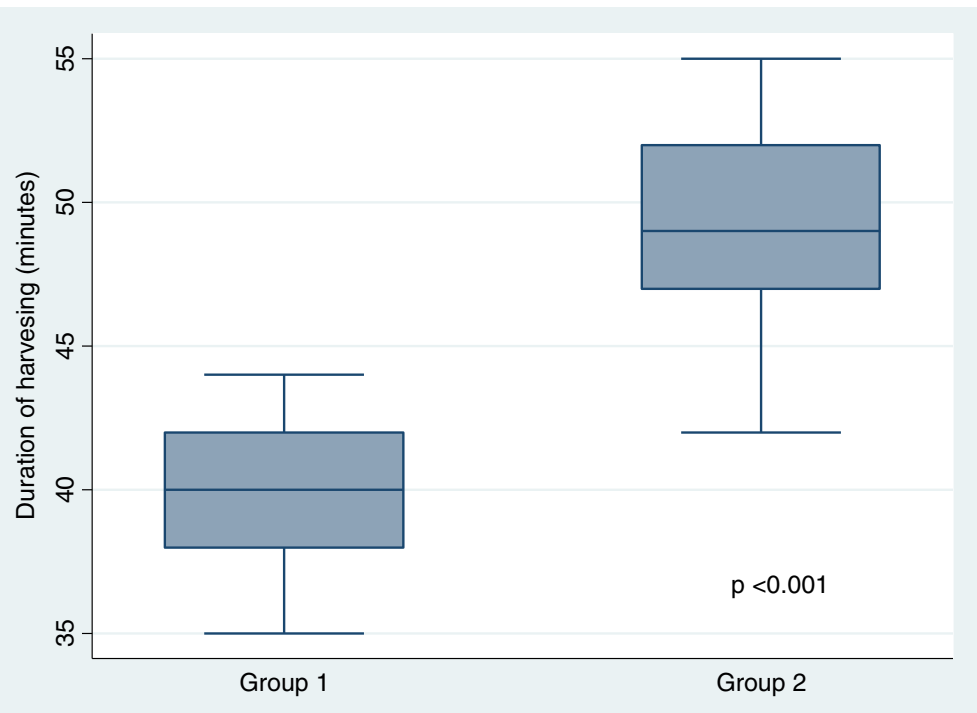

Fig. 3 Comparison of the harvest time between both groups

\section{Discussion}

The radial artery is being used as a second or third arterial conduit after internal thoracic arteries in CABG patients $[10,11]$. The radial artery has an advantage over the saphenous vein with a better long-term patency rate $[11,12]$. Radial artery harvest is relatively easy compared to other arterial conduits since its distal end is subcutaneous, and its pulsation can be felt easily; additionally, it has a large diameter, which facilitates both proximal and distal anastomosis [13]. Moreover, the radial artery has a satisfactory length [14], the forearm wound is less prone to infection compared to the leg wound, and the neurological complications are less frequent $[15,16]$. The availability of calcium channel blockers that protect the graft from arterial spasm increased the importance of radial artery harvesting and potentiated its role as one of the vital arterial grafts [17]. Open radial artery harvesting creates a long forearm scar with local wound complications. Recently, a new technique of endoscopic harvesting was widely adopted with better cosmetic results and a decrease in the rate of forearm complications $[18,19]$. However, endoscopic harvesting requires a more extended practice compared to the open technique; this is why it must be done by a well-trained practitioner who may be a non-physician [20]. This is well presented during our study in the rate of complications at the endoscopic technique that was high in the beginning as it was a new technique for us with less experience; meanwhile, after we reached a good position in the learning curve, the rate of complications started to decrease.

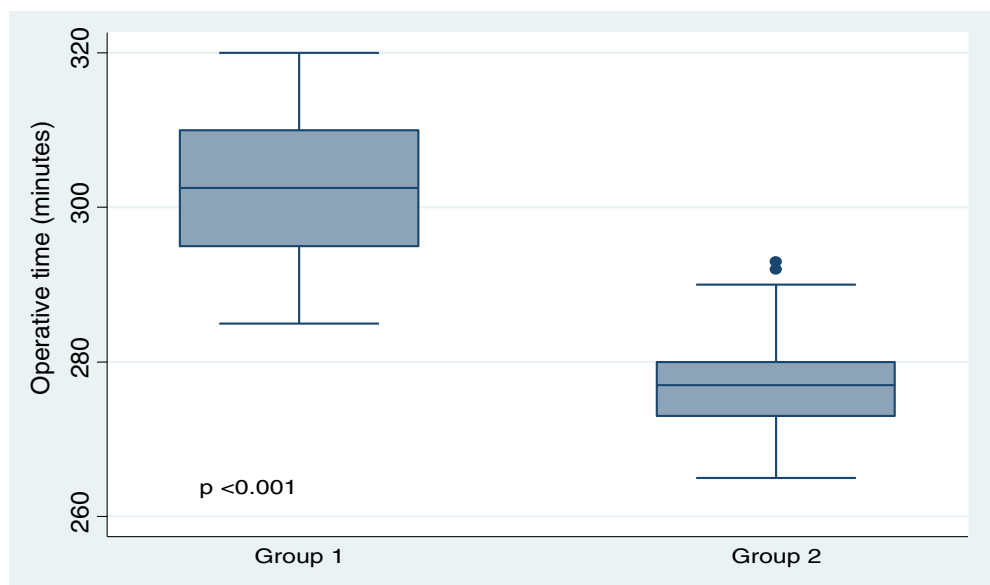

Fig. 4 Comparison of the operative time between both groups 
Table 2 Operative data comparison between the two groups

\begin{tabular}{llll}
\hline & Group 1 $(n=30)$ & Group 2 $(n=58)$ & $p$ \\
\hline Duration of harvest (min) & $40(38-42)$ & $49(47-52)$ & $<0.001$ \\
Operative time (min) & $302.5(295-310)$ & $277(273-280)$ & $<0.001$ \\
Number of grafted vessels & & & 0.353 \\
$\quad$ Three & $24(80 \%)$ & $51(87.93 \%)$ & \\
$\quad$ Four & $6(20 \%)$ & $7(12.07)$ & \\
\hline
\end{tabular}

Continuous variables are presented as median and 25th-75th percentiles and categorical variables as number and percent

Endoscopic radial artery harvesting was introduced in King Faisal Specialized Hospital in 2011, and in January 2012, this technique became regularly used. It was performed using the VASOVIEW ${ }^{\circ}$ Endoscopic Vessel Harvesting System. The objective of this study was to compare the short-term results and wound-related complications of endoscopic radial artery harvest versus open technique.

Although endoscopic radial artery harvest is less time consuming than the open technique, the whole timing of the CABG operation was longer in the endoscopic group. This time discrepancy is attributed to the sequential endoscopic radial artery and saphenous vein harvest with one VasoView; however in open technique, there are two teams harvesting both conduits at the same time.

In our study, we compared the short-term results of both endoscopic radial artery harvest and open technique in the form of local complications as forearm hematoma and infection and its effect on hospital stay. The rate of local complications was higher in the open group (hematoma and infection), the rate of hematoma was $13.85 \%$ in open group versus $3.35 \%$ in the endoscopic group, and for infection, it was $10.35 \%$ in the open group with zero cases in endoscopic technique. This is similar to other studies, and the largest casecontrol study of endoscopic radial artery harvesting reported fewer complications in comparison to open technique [21]. Other studies have shown the same,

Table 3 Comparison of the operative outcomes between both groups

\begin{tabular}{llll}
\hline & Group 1 $(n=30)$ & Group 2 $(n=58)$ & $p$ \\
\hline Hematoma & $1(3.33 \%)$ & $8(13.79 \%)$ & 0.158 \\
Wound infection & 0 & $6(10.34 \%)$ & 0.075 \\
Radial nerve injury & $2(6.67 \%)$ & 0 & 0.114 \\
Hand numbness & $6(20 \%)$ & $3(5.171 \%)$ & 0.057 \\
Chest re-exploration & $2(6.67 \%)$ & $1(1.72 \%)$ & 0.267 \\
Hospital stay (days) & $7(6-7)$ & $7.5(7-9)$ & $<0.001$ \\
\hline
\end{tabular}

Continuous variables are presented as median and 25th-75th percentiles and categorical variables as number and percent including a significant decrease in other complications such as hematomas and infections [22, 23].

Superficial radial nerve (SRN) injury and local hand numbness occurred more during endoscopic harvesting ( $20 \%$ versus $5.2 \%$ ), mostly due to excessive cauterization that occurs in the terminal part of the radial artery near the wrist reflecting less experience of harvesting. SRN runs laterally of the RA in the distal forearm and provides sensation to the volar and dorsal part of the first two fingers. This nerve may be encountered during distal forearm dissection [24, 25]. One randomized trial reporting postoperative neurological complications had been published [19]. This trial reported fewer neurological complications in the endoscopic harvest technique versus open radial artery harvest group. Endoscopic radial artery harvest reduced the risk of neurological complications in one prospective study from 10 to $0 \%$ [26]. One of the complications that occurred more frequently was chest reexploration from clipped branches of radial artery that were harvested endoscopically ( 6.75 vs. $1.7 \%$ ) because of our less experience of the endoscopic technique with excessive nearby cauterization without leaving adequate stump for clipping of the branches.

Finally, there was a statistical significance between both groups in the length of hospital stay in favor of endoscopic technique $(p<0.001)$ because of less postoperative wound complications in endoscopic group with less need to stay in hospital to manage these complications.

\section{Limitation of the study}

The major limitations are the retrospective design and the small size of endoscopic harvesting sample as it is a new technique that requires trained persons, besides no long-term follow up for the patients as regards of graft patency for both groups.

\section{Conclusions}

Endoscopic radial artery harvest is associated with shorter harvest time and shorter hospital stay. Endoscopic radial artery harvest is a safe technique with good short-term outcomes. Longer follow-up is recommended.

\section{Abbreviations}

BTT: Blunt tip trocar port; CABG: Coronary artery bypass graft; COPD: Chronic obstructive pulmonary disease; DIAG: Diagonal artery; ITA: Internal thoracic artery; LAD: Left anterior descending artery; OM: Obtuse marginal artery; PDA: Posterior descending artery; RCA: Right coronary artery; RIMA: Right internal mammary artery; SRN: Superficial radial nerve

\section{Acknowledgements}

None to declare.

\section{Author's contribution}

Single author DR MAHF was responsible for the data collection, analysis of results, and final conclusion. The author read and approved the final manuscript. 
Funding

None.

\section{Availability of data and materials}

Available upon request

\section{Ethics approval and consent to participate}

Institutional review board of King Faisal Special Hospital KSA, Number of the project is 2210 .

Consent to participate is waived as it is a retrospective study.

\section{Consent for publication}

Not applicable

\section{Competing interests}

The author declares that he/she has no competing interests.

Received: 31 October 2019 Accepted: 19 December 2019

Published online: 06 January 2020

\section{References}

1. Parolari A, Rubini P, Alamanni F et al (2000) The radial artery: which place in coronary operation? Ann Thorac Surg 69:1288-1294

2. Acar C, Ramsheyi A, Pagny JY et al (1998) The radial artery for coronary artery bypass grafting: clinical and angiographic results at five years. J Thorac Cardiovasc Surg 116:981-989

3. J Tatoulis, BF Buxton, JA Fuller, AG Royse. The radial artery as a graft for coronary revascularization: techniques and follow-up, Advances in cardiac surgery, Vol 11, : Mosby, St Louis (1999), pp. 99-128.

4. Acar C, Jebara VA, Portoghese M, Beyssen B, Pagny JY, Grare P et al (1992) Revival of the radial artery for coronary artery bypass grafting. Ann Thorac Surg 54:652-660

5. Calafiore AM, Di Giammarco G, Luciani N, Maddestra N, Di Nardo E, Angelini R (1994) Composite arterial conduits for a wider arterial myocardial revascularization. Ann Thorac Surg 58:185-190

6. Navia JL, Brozzi N, Chiu J et al (2012) Endoscopic versus open radial artery harvesting for coronary artery bypass grafting. J Cardiovasc Surg (Torino) 53: 257-263

7. Allen KB, Cheng B, Cohn W, Connolly MW, Edgerton J, Falk V, Martin J, Ohtsuka T, Vitali RM: Endoscopic vascular harvest in coronary artery bypass grafting surgery: a consensus statement of the International Society of Minimally Invasive Cardiothoracic Surgery (ISMICS). Innovations. ,2005: 51-60

8. Kim G, Jeong $Y$, Cho $Y$ et al (2007) Endoscopic radial artery harvesting may be the procedure of choice for coronary artery bypass grafting. Circ $J 71$ 1511-1515

9. Reyes A, Frame R, Brodman RF (1995) Technique for harvesting the radial artery as a coronary artery bypass graft. Ann Thorac Surg. 59:118-126

10. Acar C, Buxton B, Norsworthy C, Eizenberg N, Taggart D et al (1999) Radial artery. In: Buxton B, Frazier $\mathrm{OH}$, Westaby $\mathrm{S}$ (eds) Ischemic heart disease surgical management. Mosby, London, pp 151-157

11. Desai ND, Cohen EA, Naylor CD, Fremes SE (2004) A randomized comparison of radial-artery and saphenousvein coronary bypass grafts. N Engl J Med 351:2302-2309

12. Collins P, Webb CM, Chong CF, Moat NE (2008) Radial artery versus saphenous vein patency randomized trial. Five-year angiographic follow-up. Circulation 117:2859-2864

13. Cable DG, Caccitolo JA, Pearson PJ et al (1998) New approaches to prevention and treatment of radial artery graft vasospasm. Circulation 98: |15-|l21 discussion II21-2

14. Rodriguez E, Ormont ML, Lambert EH et al (2001) The role of preoperative radial artery ultrasound and digital plethysmography prior to coronary artery bypass grafting. Eur J Cardiothorac Surg 19:135-139

15. Allen RH, Szabo RM, Chen $J$ (2004) Outcome assessment of hand function after radial artery harvesting for coronary artery bypass. J Hand Surg Am 29: 628-637

16. Meharwal ZS, Trehan N (2001) Functional status of the hand after radial artery harvesting: results in 3,977 cases. Ann Thorac Surg 72:1557-1561

17. Brodman RF, Hirsh LE, Frame R (2002) Effect of radial artery harvest on collateral forearm blood flow and digital perfusion. J Thorac Cardiovasc Surg 123:512-516
18. Casselman FP, Meir ML, Cammu G, Wellens F, Geest RD et al (2004) Initial experience with an endoscopic radial artery harvesting technique. J Thorac Cardiovasc Surg 128:463-466

19. Patel AN, Henry AC, Hunnicutt C, Cockerham CA, Willey B et al (2004) Endoscopic radial artery harvesting is better than the open technique. Ann Thorac Surg 78:149-153

20. Connolly MW, Torrillo LD, Stauder MJ, Patel NU, McCabe JC et al (2002) Endoscopic radial artery harvesting: result of first 300 patients. Ann Thorac Surg 74:502-506

21. Shapira OM, Eskenazi BR, Hunter CT, Anter E, Bao Y, Murphy R, Lazar HL, Shemin RJ (2006) Endoscopic versus conventional radial artery harvest - is smaller better? J Card Surg. 21:329-335. https://doi.org/10.1111/j.1540-8191. 2006.00266.x

22. Kim G, Jeong Y, Cho Y, Lee J, Cho J (2007) Endoscopic radial artery harvesting may be the procedure of choice for coronary artery bypass grafting. Circ J. 71:1511-1515. https://doi.org/10.1253/circj.71.1511

23. Patel AN, Henry AC, Hunnicutt C, Cockerham CA, Willey B, Urschel HC Jr (2004) Endoscopic radial artery harvesting is better than the open technique. Ann Thorac Surg 78:149-153. https://doi.org/10.1016/j.athoracsur. 2004.03.001 Discussion 149-153

24. Royse AG, Royse CF, Shah P, Williams A, Kaushik S, Tatoulis J (1999) Radial artery harvest technique, use and functional outcome. EurJ Cardiothorac Surg. 15:186-193

25. Meharwal ZS, Trehan N (2001) Functional status of the hand after radialartery harvesting: results in 3977 cases. Ann Thorac Surg. 72:1557-1561

26. Patel AN, Henry AC, Hunnicutt C, Cockerham CA, Willey B, Urschel HC Jr (2004) Endoscopic radial artery harvesting is better than the open technique. Ann Thorac Surg. 78:149153. https://doi.org/10.1016/j.athoracsur. 2004.03.001

\section{Publisher's Note}

Springer Nature remains neutral with regard to jurisdictional claims in published maps and institutional affiliations.

\section{Submit your manuscript to a SpringerOpen ${ }^{\circ}$ journal and benefit from:}

- Convenient online submission

- Rigorous peer review

- Open access: articles freely available online

- High visibility within the field

- Retaining the copyright to your article

Submit your next manuscript at $\boldsymbol{\nabla}$ springeropen.com 